\title{
Potential and Challenges in Use of Thermal Imaging for Humid Region Irrigation System Management
}

\author{
Steven J. Thomson (Corresponding author) \\ USDA, ARS, CPSRU, PO Box 350, Stoneville, MS, USA \\ Tel: 1-662-686-5240Ｅ-mail: steve.thomson@ars.usda.gov
}

Claudiane M. Ouellet-Plamondon

Department of Engineering, University of Cambridge, Cambridge CB21PZ, UK

Sherri L. DeFauw

USDA, ARS, NEPSWL, New England Plant, Soil, \& Water Lab, Univ. of Maine, Orono, ME, USA

Yanbo Huang \& Daniel K. Fisher

USDA, ARS, CPSRU, PO Box 350, Stoneville, MS, USA

Patrick J. English

Delta Research and Extension Center, Mississippi State University, Stoneville, MS, USA

Received: October 26, 2011

doi:10.5539/jas.v4n4p103
Accepted: November 24, $2011 \quad$ Online Published: February 2, 2012

URL: http://dx.doi.org/10.5539/jas.v4n4p103

\begin{abstract}
Thermal imaging has shown potential to assist with many aspects of irrigation management that include scheduling application of water and detecting leaking irrigation canals and delivery systems. There are particular challenges for use of thermal imaging for scheduling irrigation in humid subtropical climates, which include the need for fine delineation of canopy temperatures under low vapor pressure deficits, proper accounting for micrometeorological conditions, and altitude effects on canopy temperature represented at the camera. A review of pertinent issues involved in using thermal methods for sensing canopy temperature is presented that can be applied to the imaging problem. Altitude effects were demonstrated in a new field experiment, and multiple regression was used to indicate and model weather and altitude effects. The use of spatial statistics was shown to enhance the value of thermal imagery using sensor fusion. Thermal imagery was also useful in detecting leakage from irrigation systems in the context of overall irrigation system management.
\end{abstract}

Keywords: Remote sensing, Thermal imaging, CWSI, Canopy temperature, Irrigation, Spatial statistics

\section{Introduction}

Canopy temperature has proven its utility for detection of crop water stress over large field scales, but has yet to find widespread acceptance as a tool for water management based on canopy temperature status. Temperature of a crop canopy is related to general physiological status of the crop (Inoue, 1990), which includes photosynthesis, respiration, and stomatal conductance. As crop water status is a major component influencing canopy temperature, remote measurement of this variable over pertinent phenological stages could optimize water application amounts.

The use of canopy temperature for water management in humid subtropical climates is considered problematic with current technologies. As the crop begins to show signs of stress, small increases in canopy temperature can be difficult to detect with adequate resolution (Thomson and Sullivan, 2006). Prevailing low vapor-pressure deficit (VPD), which is characteristic of a humid subtropical climate, reduces the magnitude of natural crop 
cooling by evaporation. Compounding the problem is frequent and periodic cloud cover (characteristic of this climate), which rapidly alters canopy temperature (Pennington and Heatherly, 1989). Inoue (1990) acknowledges that physiological measurements cannot be analyzed and interpreted correctly without concurrent micrometeorological data. New technological approaches are thus needed to overcome these complications so crop- and soil-specific needs can be met with the assistance of thermal detection methods. In this paper, we examine pertinent research and present new experiments illustrating use of canopy temperature as a basis for determining temporal changes in crop water stress. The review portion is not all-inclusive but attempts to highlight issues of particular significance. We discuss positive aspects as well as challenges for using thermal techniques from aircraft-based remote sensing platforms and introduce a method that uses a fusion of visible, near infrared (NIR), and thermal imagery coupled with spatial statistics to help identify areas prone to early water/heat stress in highly heterogeneous cotton fields, early senescence promoted by water/heat stress, and field areas that might require variable application of defoliants/harvesting aids. Thermal imagery has been beneficial for our work in supporting irrigation system diagnostics, and examples are presented for detection of water leakage from irrigation canals and polypipe systems.

\section{Background - thermal Sensing for Detection of Crop Water Stress}

\subsection{Crop Water Stress Index (CWSI)}

Canopy-to-air temperature difference (CATD) can provide information on crop energy status. As the leaf transpires, it cools relative to the surrounding air; however as water becomes limiting, transpiration is reduced and the leaf temperature increases. Under certain environmental conditions, this measurement alone may be sufficient to determine water stress for specific crops (Gardner et al., 1992a, 1992b). Most of the successful work in this area has been accomplished in arid, semiarid, or Mediterranean climates, as large CATD permit adequate sensitivity for water management. Mathematical relationships using canopy temperature have been developed with an eye on practical irrigation scheduling (Pinter and Reginato, 1981; Stockle and Dugas, 1992; Colaizzi et al., 2003; Cohen et al., 2005).

A well known index that indicates a relationship between canopy temperature and the difference between "well watered baseline" and "high stress" canopy temperatures is the Crop Water Stress Index (CWSI) (Jackson et al., 1981). Most studies have used the crop-water stress index (CWSI) for full canopies; however, complications arise when attempting to apply this index in fields with partial canopy cover. Regardless of the climate characteristics (humid or arid), early season CWSI values are particularly difficult to obtain with partial canopies. In the early growing season when plants are small or populations are sparse, a portion of the soil surface is usually viewable by infrared thermometer when canopy temperature measurements are made (Irmak et al., 2000). Although ground-based infrared sensing systems and hand-held devices could be physically manipulated to provide temperature of the canopy only by viewing at oblique angles or close-up, a more realistic approach is to consider the effect of soil cover and develop methods to determine the relative influence of canopy and soil on remotely sensed temperature. Moran et al. (1994) developed a method to combine spectral vegetation indices with composite surface temperature measurement to allow application of CWSI theory to partially vegetated fields. The authors developed a vegetation index/temperature (VIT) bounded trapezoid to plot surface-air temperature difference against fractional vegetation cover.

Emekli et al. (2007) evaluated the CWSI for irrigation scheduling of bermudagrass using infrared thermometry. The authors examined four irrigation treatments corresponding to levels of evaporation as measured by Class A evaporation pan; a non-irrigated treatment was also implemented. Both soil water content and potential were monitored using a neutron probe and tensiometers, and CWSI values were empirically determined. In this study, the visual quality of bermudagrass was monitored seasonally using a Munsell color scale. The authors concluded that the CWSI could be used as a criterion for irrigation timing of bermudagrass, and an acceptable color quality could be sustained seasonally if the CWSI value stayed below about 0.10. Kar and Kumar (2007) used a lower and upper limit for calculation of the CWSI in groundnut under irrigated ecosystem. The lower baseline was developed with linear regression analysis for measurements in the cold season after the crops had received full irrigation on humid and dry days, whereas the upper limit was determined by monitoring plants and recording when the transpiration rate closely approached zero. Kashefipour et al. (2006) defined a linear relationship between yield and CWSI for Spring Corn by implementing five irrigation treatments. Maximum yield occurred at a CWSI value of 0.05 and maximum water productivity occurred at a CWSI of 0.15 for their experiment.

Idso (1982) indicated the importance of accurately specifying the non-stressed baseline for CWSI calculation. Baseline from an artificial wet reference surface (Meron et al., 2003) was used to specify the wet CWSI baseline, $\mathrm{T}_{\mathrm{cm}}$ for a study by Cohen et al. (2005), who used the CWSI to estimate leaf water potential. Use of this reference 
surface greatly simplified use of the CWSI, as it was easy to maintain as compared with well-watered crop sections. The authors used a Thermacam model PM545 thermal imaging camera mounted 5-m above the ground, pointing downward to image the canopy. Camera resolution was adequate to distinguish leaves from soil so only leaves could be analyzed. The authors found very good correlation between CWSI and leaf water potential measured using an ARIMAD 1 pressure chamber. Alchanitis et al. (2010) compared theoretical and empirical approaches for estimating leaf water potential and found that empirical temperature baselines performed better than those derived from energy balance equations. Normalization of the CWSI can be complicated under changing atmospheric conditions. Grant et al. (2007) addressed the issue of leaf angle and suggested that average temperatures over the canopy containing several leaves within the measurement area could reduce the impact leaf angle variation in grapevine. The authors indicated that thermal imaging can be useful to detect stressed vs. non-stressed areas as their thermal measurements vs. porometry (indicating stomatal conductance) have suggested. Alchanatis et al. (2006) indicated the difficulties present in adopting the crop water stress index (CWSI) for practical irrigation management. Temperatures of the relevant crop canopy, of the general leaf population, and of the soil background can be mixed, altering the represented value of canopy temperature. Practical use of the index will require methodologies to automatically process thermal and associated imagery, which includes partitioning of shaded and exposed portions of the canopy (Jiménez-Bello et al., 2011). The authors developed a system to automatically analyze and process simultaneous thermal and RGB imagery; the latter used to identify vegetative portions from the image using unsupervised classification.

\subsection{Time-temperature Thresholds}

Researchers have used the canopy temperature measured by infrared thermometer (IRT) with time thresholds to assist with practical irrigation scheduling (Wanjura et al., 1995; Mahan et al., 2005). The idea was to signal irrigation based on the amount of time a crop-specific canopy temperature threshold is exceeded by modeling the CWSI as a function of environmental factors. The amount of time that calculated canopy temperature is above the threshold temperature can be used to schedule irrigation. Peters and Evett (2008) developed a completely automated center pivot irrigation system based on this concept. Canopy temperature data were logged from sixteen calibrated IRTs on the center pivot lateral. Minutes that the canopy temperature as read by IRTs exceeded a threshold temperature were accumulated during the day. If the daily total exceeded the time threshold at the end of the day, irrigation of a fixed depth was initiated. The authors did not accumulate time at all for their time-temperature threshold method if relative humidity was too high (VPD too low). Yield of soybeans was compared between irrigation scheduled using the time-temperature threshold method and weekly scheduled irrigation using a neutron probe to determine the amount of water required to replenish the profile to field capacity. No significant differences were found between water use efficiency or yield between the two scheduling methods.

\subsection{Plant Response to Variations in Solar Radiation}

No matter which scheme is developed to utilize canopy-air temperature difference for determination of crop water stress, plant response to varying solar radiation and cloud cover effects needs to be considered. Variable insolation is prevalent in humid regions and it is thus especially critical to adequately resolve CATD during periods of low vapor-pressure deficit. To help quantify these cloud cover effects, Pennington and Heatherly (1989) logged solar radiation using a pyranometer and canopy temperature using an infrared temperature sensor. The authors then plotted solar radiation (SR) against canopy-air temperature difference for cotton, and obtained a good linear fit but with a fair amount of scatter $\left(\mathrm{R}^{2}=0.84\right)$. The canopy typically took about $100 \mathrm{~s}$ to stabilize to a new temperature after a cloud passed over the field. When these time lags were accounted for, a much better fit of the canopy-air temperature difference/solar radiation data $\left(\mathrm{R}^{2}=0.98\right)$ was obtained.

\subsection{Aerial Determination of Canopy Temperature}

Imaging sensors have been used on aerial platforms to determine canopy and soil temperature. These systems have the potential for rapidly determining the onset of water stress in the whole field or sections of a field. Thermal sensing from easily scheduled aerial platforms might hold the key to practical adoption of canopy temperature-based technologies for irrigation scheduling if proper application and analysis techniques are employed.

Early work by Bartholic et al. (1972) used an airplane-mounted Texas Instruments (TI) RS-14 scanner to measure thermal radiance in the 8 to $14 \mu \mathrm{m}$ wavelength interval. A radiance difference of $6 \mathrm{C}$ was observed between the most and least water-stressed plots. Heilman et al. (1976) used an aerial thermal scanner at aircraft altitudes of 610 and $1220 \mathrm{~m}$ to measure canopy temperatures for estimation of evapotranspiration (ET). Atmospheric attenuation produced errors of 1 to $6 \mathrm{C}$ in scanner measurements, so a correction procedure relating 
temperature error to atmospheric perceptible water was applied. Relative errors ranged from +62.5 to $-43.6 \%$ between lysimetric and model-based estimates of ET. The effect of temperature error on ET was partially influenced by thermal diffusion resistance, which was derived from wind and air temperature profiles. Smith et al. (1989) studied how radiative surface temperature of a water-stressed crop could be used to indicate sources of variability in soil characteristics. Instrumentation included a Daedalus thermal scanner (DEI-100) with a 120-degree field-of-view, mounted in an aircraft flown at 1000-m altitude. The authors also measured ground-based surface temperatures with an Everest Interscience Series 100 handheld IR thermometer. Analysis of data indicated patterns in radiative surface temperature obtained using the aerial system could be related to spatial differences in soil type and water availability under complete crop cover.

As part of a multifaceted remote sensing program, Goodrich et al. (1998), Qi et al. (1998), and Moran et al. (1998) used an Agrometrics single-band thermal video system to measure surface temperatures for ET determination over a riparian zone. The aerial system gave $0.5 \mathrm{~m}$ ground resolution and covered spectral wavelengths of 8 to $12 \mu \mathrm{m}$. Preliminary results from Qi et al. (1998) showed that spatial ET could be mapped using thermal images obtained from the single-channel Agrometrics sensor. Micrometeorological factors such as wind speed and solar radiation seemed to influence transpiration more than stomatal conductance for a study on grassland (Shimoda and Oikawa, 2008). González-Dugo et al., (2006) indicated that canopy temperature determined by aerial remote sensing (ATLAS sensor) was very sensitive to variations in plant water stress for moderately stressed crops and had a linear relationship with CWSI. This has positive implications for irrigation scheduling since canopy temperature within the moderate stress range is where most irrigation decisions are made. Berni et al. (2009) used an unmanned aerial vehicle equipped with both a thermal and six-band multispectral camera to map biophysical parameters and crop water stress. This image fusion technique determined the potential of using the multispectrally-based photochemical reflectance index (PRI) to map crop water stress. PRI was well correlated with canopy temperature, and the study highlighted the importance of atmospheric correction as a function of acquisition altitude. Thomson et al. (2005) used a Raytheon Palm-IR thermal imaging camera, which indicated visible differences in canopy temperature before and after irrigation. However, varying cloud cover appeared to alter image contrast and relative temperature representations within a field for other image pairs. Temperature effects due to shading have been determined or modeled (Zhang et al., 2001; Leinonen and Jones, 2004), and their observations of cloud cover effects were consistent with those of Pennington and Heatherly (1989).

\section{New Experiments Using Thermal Imagery for Crop Water Stress Detection and Irrigation System Diagnostics}

3.1 Environmental Effects on Representation of Canopy Temperature and Temporal Crop Response to Water Stress

\subsubsection{Procedures}

Thermal imagery was obtained of a field planted in soybeans (Glycine max) at the USDA ARS Mechanization Farm near Stoneville, MS, USA. Soil moisture data were obtained to give an indirect indication of pending crop water stress that could be associated with readings from both ground-based and aerial canopy-temperature sensors. Previous research showed little correlation $(r=0.22)$ between data from soil water sensors and canopy-air temperature difference as measured by ground-based IRTs (Thomson et al., 2005). However, other variables that could influence readings from the IRTs were not accounted for. More importantly however, soil water sensors measure water potential within a small zone of influence in the soil and variability is expected to be high within a field. In our case, soil water sensors provided useful information on wetting trends due to rainfall or irrigation and drying trends for comparison of imagery on a temporal basis. For fine textured alluvial soils typical of the Midsouth US, soil drying in excess of one week before irrigation commences is not uncommon.

Watermark 200-SS soil water sensors (SWS) were installed at four stations and at three depths per station (23, 46, and $69 \mathrm{~cm}$ ) of a center pivot irrigated field of soybeans (Fig. 1, Fig. 6) planted in a clay soil of the Sharkey series (very-fine, smectitic, thermic Chromic Epiaquerts). In the early morning, these sensors were read along with readings of leaf temperature (three leaves per station) using both an Exergen IRT/C-K-80F/27C and Apogee IRTS-Pc precision IRT; the latter was purchased with custom calibration coefficients. Air temperature, relative humidity, and wind speeds were measured at the moment of fly-over using a Kestrel 4000 Pocket Weather Tracker (Table 1). Photosynthetically Active Radiation (PAR) was measured using a Li-cor Li-191SB quantum sensor and Li-1000 data logger. Except for the Watermark readings, measurements were repeated in the early afternoon. Rainfall and irrigation amounts (Fig. 2) were measured using a Productive Alternatives rain gauge. 
An Electrophysics PV-320T thermal imaging camera (320 X 240 pixel resolution) was used in an Air Tractor 402B agricultural airplane (Fig. 3) to obtain thermal imagery in the $7-14 \mu \mathrm{m}$ spectral range. The pilot was instructed to fly at an altitude of approximately $457 \mathrm{~m}(1500 \mathrm{ft})$ over the 3-ha field between 10:30 and 13:30 for all flights. Approximate altitudes for each flight were recorded by the Satloc Airstar M3 GPS receiver with Wide Area Augmentation System (WAAS) differential correction. Although vertical accuracy is only within $6 \mathrm{~m}$ typically for WAAS-corrected receivers (Wilson, 2011), this was deemed to be adequate as long as an offset was applied to account for inaccuracy of represented elevation at ground-level.

Images were captured and processed using Electrophysics Velocity 2.1 image analysis software. For a reasonable span and good resolution of temperature represented by the images, a range between 28 and $33 \mathrm{C}$ ( 83 and $93 \mathrm{~F}$ ) was chosen. Within this range, the maximum temperature difference within the field was typically about 3 to $4 \mathrm{C}$. Temperatures could be represented either by digital numbers (DNs), energy values, or actual temperature. Because temperature resolution was greater using DNs, a relationship of DN vs. temperature was made within the temperature range chosen.

\subsubsection{Results}

Over a full canopy, canopy temperature represented by the camera was 4 to $6 \mathrm{C}$ cooler than temperatures measured of single leaves using Apogee precision IRTs. This difference was smaller when the IRTs measured several leaves of a single plant later in the season, taking care not to include soil background. Subsequent analysis indicated a linear influence of altitude on canopy temperature (Fig. 4). Data for Fig. 4 were obtained at several altitudes flown by the pilot over the same field. Since pixel resolution depended on altitude and a single point would represent different ground area at different heights, a field of soybeans in a uniform well-irrigated field of Sharkey series clay soil was chosen that exhibited spatially uniform canopy temperature as determined by thermal imaging. The pilot flew upwards in a spiral fashion and back down to obtain several data points. Using the Electrophysics Velocity 2.1 software, canopy temperatures were later extracted from the same spatial location of uniform temperature on the image. All weather variables were obtained the instant a single altitude was flown.

Multiple Regression Analysis using SAS 9.1.3 indicated that altitude explained 58\% of the variability in canopy temperature (Fig. 4). Standard error of the estimate $=0.59$ and the model was statistically significant at the 0.01 level. With additional variables introduced, [Altitude + PAR] accounted for $73 \%$ of the variability in canopy temperature and [RH + altitude] accounted for $76 \%$ of the variability in canopy temperature.

One temperature value was also obtained as a cloud passed over (not shown in Fig 4). When the regression was re-cast with this data point included (Fig. 5), altitude then explained $41 \%$ of the variability in canopy temperature. Standard error of the estimate $=0.81$ and the model was statistically significant at the 0.05 level. With additional variables introduced, [Altitude + PAR] accounted for $76 \%$ of the variability in canopy temperature. When relative humidity (RH) or (Air Temperature) ${ }^{2}$ was added to the model as a third variable, $\mathrm{R}^{2}$ increased to 0.87 .

The effects indicated above accounted for much of the differences in canopy temperature, but canopy shading appeared also to be a significant effect as a single pixel from the camera represented a composite of shaded and sunlit leaves. This is due to the limited spatial resolution of the camera. At $457 \mathrm{~m}$ altitude, the $320 \mathrm{X} 240$ pixel resolution translates into about $0.93 \mathrm{~m} /$ pixel ground resolution for the field of view of that camera. The degree of this shading effect was noticed to vary slightly with time of day and viewing angle, but this effect was not quantified. Figure 6 illustrates images of a soybean canopy obtained with the Electrophysics camera at $460-\mathrm{m}$ altitude. Dark areas indicate cooler temperatures; lighter shades indicate warmer temperatures. A constant range of temperatures between 28 and $33 \mathrm{C}(83$ and $93 \mathrm{~F}$ ) corresponding to pixel values was set for consistency between images. This is a relatively narrow range within which the full range of color differences could be seen in a field. Typical canopy temperatures as measured by the camera ranged from 28 to $31 \mathrm{C}(83$ and $88 \mathrm{~F}$ ). Rainfall on days 195, 199, and 202 kept the soil environment adequately replenished with water (Fig. 2). This was confirmed by readings from soil water sensors (Fig. 1). The image obtained on day 207 can serve as a baseline for comparison with subsequent days. Rainfall totalled $1.9 \mathrm{~cm}$ over days 208 and 209 but soil water sensor (SWS) readings indicated slightly drier soil conditions on day 214. The image for day 214 appears to show a warmer canopy overall, but the high degree of temperature increase was not consistent with the crop's apparent stress level as indicated indirectly by SWS. Altitude of flight was lower for this run, as was PAR. Weather was generally clear on this date however, so it is not clear if the low PAR value obtained was short-lived or if the plants had time to change temperature within a 100-s window (Pennington and Heatherly, 1989). Spatial differences in canopy temperature were well defined for days 221 and 229. This pair of images indicates how a temporal comparison should look if conditions are consistent between days. The angle and 
location of image capture, solar radiation, and flight altitude were all closely comparable. No significant rainfall occurred between those days, and temporal analysis of Watermark readings indicated higher soil-water potential at the $46 \mathrm{~cm}$ depth at three out of four stations on day 229.

\subsection{Spatial Relationships Involving Canopy Temperature}

Water management is one important aspect of crop production, but the crop production system frequently requires multiple decisions to be made. Nowhere is this more apparent than with cotton production. Cotton management involves many factors that must work together properly to ensure a high yielding and quality crop. Depending on soil texture, nutrient levels, and other field characteristics, some field areas have lower yield potential and have differing needs with regard to timing of water application and insecticide management. We thus decided to investigate sensor fusion methods that include thermal imaging to delineate field areas requiring more attention with regard to water and pest management.

\subsubsection{Procedures}

Thermal images acquired over a five-week interval from July through August 2006 (using an Electrophysics PV-320T camera mounted in an agricultural aircraft flown at an altitude of $460 \mathrm{~m}$ ) were composited (Fig. 7) to produce a cumulative thermal map of a cotton canopy. This 2.3-ha field was managed uniformly with regard to nutrient levels and was non-irrigated. In addition to the thermal images, two Color Infrared (CIR) images (12-bit, $0.15 \mathrm{~m}$ resolution) were obtained using the Emerge Digital Sensor System (DSS) (Emerge Sensor Group, Andover, MA, USA); this camera was flown at an altitude of $600 \mathrm{~m}$ on 10 July and 24 August 2006. Images were processed using an intensity normalization method followed by calculation of Normalized Difference Vegetation Index (NDVI). These two normalized CIR images were also processed using Isodata unsupervised classification (Jensen, 1996) to establish two classes (coded $0=$ no vegetation and $1=$ vegetation); zonal means were subsequently calculated for each image (i.e., resampled to $1-\mathrm{m}$ resolution) resulting in assessments of percent cover. Canopy cover change was determined by subtracting the classified July image from the vegetation mapped in late August.

\subsubsection{Results and Discussion}

Highly significant patterns of yield linked to the thermal zonation were evident in this irrigated field (using a bivariate Local Indicator of Spatial Association or LISA map) with close to $65 \%$ of the field extent at $p \leq 0.01$ and $15 \%$ of the field area at $0.01<p \leq 0.05$. Another bivariate LISA map, using GeoDa (Spatial Analysis Laboratory, University of Illinois, Urbana-Champaign, IL, USA) charts significant autocorrelations $(\mathrm{p} \leq 0.05)$ between cotton canopy cover change and the cumulative thermal maps (Fig. 7A).

Low canopy cover change was coupled with the lowest cumulative canopy temperatures (depicted in dark shade). Similarly, the adjacent areas of the field (portrayed in lighter shade) displayed relatively high canopy cover change paired with low canopy temperature change. The second bivariate LISA map (comparing patterns of yield with in-season canopy cover change - Fig. 7B), resolves four field-scale production zones including: (1) high yielding areas with low canopy cover change; (2) a more scattered grouping of high yielding areas paired with relatively high canopy cover change; (3) "stressed" portions of the field with low yield and low canopy cover change; and (4) low yielding areas coupled with relatively high canopy cover change. Ground-truthing demonstrated that from mid to late August, cotton plants subjected to consistently high temperatures had 50 $90 \%$ open boll. These results indicate that composited thermal imagery combined with tracking canopy cover change at key phenological stages could be useful for the in-season prediction of yield potential as well as early senescence promoted by heat/water stress in highly heterogeneous cotton fields. Management of water (termination of irrigation) is tied to phenological stage in cotton, and maps such as these could also foster the development of site-specific insecticide applications to protect high-yielding areas and promote cost-effective application of defoliants/harvest aids. Assuming an irrigation system is capable of varying water application rates or can be scheduled by zones, spatial differences as indicated in thermal imagery could be useful for irrigation timing decisions on select portions of the field.

\subsection{Irrigation System Diagnostics}

Detection of water leaks in irrigation systems has been successfully accomplished using thermal imagery. Huang et al. (2009) used a multispectral imaging system that included an Indigo Systems Merlin Thermal IR 12-bit camera (Niceville, FL, USA) and dual digital Dalsa 1M30 cameras (Waterloo, Ontario, Canada) fitted with interference filters for the Red $(0.66 \mu \mathrm{m})$ and NIR $(0.8 \mu \mathrm{m})$ wavelengths. This imaging system was mounted on an aircraft and flown at low altitude to collect the images over the irrigation canal systems in the Lower Rio Grande Valley of Texas, USA. Thermal, Red, and NIR images were collected of 24 selected canal segments 
within 11 irrigation districts in this region. In image analysis, the thermal images worked well in detecting leaks from concrete canal segments, and ancillary data from the higher resolution Red, NIR, and NDVI images were used to indicate the presence of trees or shadows that might normally be seen as water leakage if thermal imagery alone were used. NDVI images were also valuable in detection of areas of higher grass density around earth canal segments, which might be inferred as higher seepage in those areas. The results of image analysis indicated that 140 sites had possible canal leakage problems (point leak and/or seepage). A site evaluation was performed to document the type and severity of the leaks at 28 of the sites. Twenty-six sites were confirmed to have leaks, representing a success rate of $93 \%$. The method of fusion of information from thermal, Red and NIR images could have widespread application for detecting leaks and seepage in irrigation systems.

Another example from our research illustrates how useful information on water leakage and other irrigation-related characteristics can be obtained. Figure 8 illustrates an image taken over a corn/soybean rotation study in the Spring of 2005 at the USDA ARS Stoneville research fields. Moving from left to right in the image, the soybean soil environment was drying from the previous irrigation causing higher canopy temperature as indicated by lighter shaded areas. To the right of that field, corn was being irrigated or was just recently irrigated. The irrigation pipe at the top of the corn field is a dark shade indicating that water was still flowing. Lighter "hot spots" can be seen in the field, which indicate restricted water flow to these areas most likely due to trash or high spots. If these are determined to be high spots, careful field levelling might be in order. The area to the right of the corn field shows system leakage down several furrows of a soybean field (indicated by the darker shade). To the right of that leakage is evidence of a previous irrigation that was stopped a few days before, as this field was irrigated inadvertently. This error in irrigation was not apparent to the naked eye at the time of image acquisition.

\section{Summary - Research Advances, Needs, and Challenges}

Challenges exist for improving thermal imagery products to accurately track spatiotemporal changes in canopy-air temperature difference (CATD). An experiment that varied altitude also considered variable solar radiation, wind, ambient air temperature, and $\mathrm{RH}$, and preliminary relationships were developed over a uniform field of planted soybeans. Thermal imagery has shown utility in providing geospatial information as one component of a multi-sensor implementation to determine field areas requiring more attention with respect to timely application of water and other field inputs. Spatial statistics has shown utility in tracking variability in the field, and the example presented herein from our research was for cotton, a crop that requires intensive management and fine-scale application of insecticide, harvesting aids, and water. Using spatial information and ground truthing, a variable-rate irrigation system could be used to apply water by zones, paying particular attention to those areas prone to stress using prior information. Although on-the-go application using thermal imagery might be feasible using time-temperature thresholds or similar methods that rely on CATD, methods for delineation of CATD that account for weather variables and height of image acquisition need to be fine-tuned if canopy temperatures are to be acquired from aerial platforms.

Successful application of canopy temperature-based strategies for irrigation in humid subtropical climates includes many challenges. The following attempts to summarize these challenges and indicate progress.

1) Cameras or ground-based sensors must demonstrate adequate spectral or measurement resolution of canopy temperature difference as the crop begins to require water replenishment. It may not be feasible to track temporal trends in crop water stress when prevailing VPD is very low. This situation is commonplace in many areas of the Southern US although not as consistent in the Midsouth US. This limitation has also been realized in previous research.

2) Time lags in plant response due to either step changes in incoming solar radiation or haze need to be considered when using any thermal detection method. From aerial imagery, we have noticed lower image contrast and radiometric resolution on cloudy days so temperature readings should best be made under cloudless conditions and carefully monitored for haze that can influence canopy temperature.

3) Since much research has been done with regard to yield response and stress levels associated with CWSI, this index can be utilized either with aerially obtained canopy temperature data or with corroborating ground IRT measurements. To make the CWSI equation palatable for practical use, a mobile water surface can be used to obtain wet canopy (baseline) temperature as previous research has suggested.

4) In an experiment we conducted that considered varying altitude, altitude accounted for $58 \%$ of the variability in canopy temperature. When the variable solar radiation (SR) was added, this value increased to $73 \%$. Variables altitude and RH accounted for $76 \%$ of the variation. These results were specified during periods on cloudless periods, a condition that should be met if at all possible when determining canopy temperature. The significant 
increase in $\mathrm{R}^{2}$ by introducing SR as a variable indicates high sensitivity to this variable. Relationships like these could be used to spectrally re-scale thermal imagery for temporal comparison.

5) We have found that use of a weather instrument to record instantaneous readings at the moment of imaging was more convenient and accurate than using logged data from a nearby weather station. Leaf angle effects from temperatures obtained ground truthing IRTs could be reduced by averaging temperatures over canopy sections instead of from single leaves, as previous research has indicated. Our experience with post-processed thermal imagery indicates that images should be captured from moving digital video at a consistent viewing angle; images should be obtained at the same time of day.

6) Fusion of sensing methods that include thermal sensing and multispectral imaging may ultimately be more beneficial to facilitate crop management. Our use of geospatial yield, stress, and canopy cover relationships have shown utility in spotting areas of a field that require more attention, and this information could assist in developing a water management plan that suits a particular field based on soil texture and environment. As water management is frequently interrelated with management of other inputs (such as application of insecticide and harvesting aids for cotton), fusion of imaging methods can provide information on management of water as they relate to maturity-based indices.

\section{References}

Alchanatis, V., Cohen, Y, Cohen, S., Moller, M., Meron, M., Tsipris, J., Orlov, V., Naor, A., \& Charit, Z. (2006). Fusion of IR and multispectral images in the visible range for empirical and model-based mapping of crop water status. American Society of Agricultural Engineers (ASABE) Technical Paper No. 061171. St. Joseph, MI. USA: ASABE.

Alchanatis, V., Cohen, Y, Cohen, S., Moller, M., Sprinstin, M., Meron, M., Tsipris, J., Saranga, Y., \& Sela, E. (2010). Evaluation of different approaches for estimating and mapping crop water status in cotton with thermal imaging. Precision Agriculture, 11, 27-41. http://dx.doi.org/10.1007/s11119-009-9111-7

Bartholic, J.F., Namken, L.N. \& Weigand, C.L. (1972). Aerial thermal scanner to determine temperatures of soils and of crop canopies differing in water stress. Agronomy Journal, 64, 603-608. http://dx.doi.org/10.2134/agronj1972.00021962006400050016x

Berni, J.A.J., Zarco-Tejada, P.J., Suárez, L., \& Fereres, E. (2009). Thermal and narrow-band multispectral remote sensing for vegetation monitoring from an unmanned aerial vehicle. IEEE Transactions on Geoscience and Remote Sensing. 47(3), 722-738. http://dx.doi.org/10.1109/TGRS.2008.2010457

Cohen, Y., Alchanatis, V., Meron, M., Saranga, Y., \& Tsipris, J. (2005). Estimation of leaf water potential by thermal imagery and spatial analysis. Journal of Experimental Botany, 56(417), 1843-1852.http://dx.doi.org/10.1093/jxb/eri174

Colaizzi, P.D., Barnes, E.M., Clarke, T.R., Choi, C.Y., \& Waller, P.M. (2003). Estimating soil moisture under low frequency surface irrigation using crop water stress index. Journal of Irrigation and Drainage Engineering, 129 (1), 27-35. http://dx.doi.org/10.1061/(ASCE)0733-9437(2003)129:1(27)

Emekli, Y., Bastug, R., Buyuktas, D., \& Emekli, N.Y. (2007). Evaluation of a crop water stress index for irrigation scheduling of bermudagrass. Agricultural Water Management, 90, 205-212. http://dx.doi.org/10.1016/j.agwat.2007.03.008

Gardner, B.R., Nielsen, D.C., \& Shock, C.C. (1992a). Infrared thermometry and the crop water stress index. I. History, theory, and baselines. Journal of Production Agriculture, 5(4), 462-466. [Online] Available: http://www.ars.usda.gov/SP2UserFiles/Place/54070000/1990-1999documents/266\%201992\%20GardnerJPA.pdf (October 19, 2011).

Gardner, B.R., Nielsen,D.C., \& Shock, C.C. (1992b). Infrared thermometry and the crop water stress index. II. Sampling procedures and interpretation. Journal of Production Agriculture, 5(4), 466-475. [Online] Available: http://www.ars.usda.gov/SP2UserFiles/Place/54070000/1990-1999documents/267\%201992\%20Gardner\%20JP A.pdf (October 19, 2011).

Goodrich, D., Moran, M.S., Scott, R., Qi, J., Williams, D., Unkrich, C., Schaeffer, S., Mac Nish, R., Maddock, T., Goff, B., Toth, J., Hipps, L., Cooper, D., Schieldge, J., Chehbouni, A., Watts, C., Shuttleworth, J., Hartogensis, O., DeBruin, H., Kerr, Y., Marsett, R., \& Ni, W. (1998). Seasonal estimates of riparian evapotranspiration (consumptive water use) using remote and in-situ measurements. Special Symposium on Hydrology, American Meteorological Society, Phoenix, AZ. [Online] Available: http://www.tucson.ars.ag.gov/salsa/research/research_1997/AMS_Posters/ams_posters.html (October 19, 2011). 
González-Dugo, M.P., Moran, M.S., Mateos, L. \& Bryant, R. (2006). Canopy temperature variability as an indicator of crop water stress severity, Journal of Irrigation Science, 24, $233-240$. http://dx.doi.org/10.1007/s00271-005-0022-8

Grant, O., Tronina, L., Jones, H.G., \& Chaves, M. M. (2007). Exploring thermal imaging variables for the detection of stress responses in grapevine under different irrigation regimes. Journal of Experimental Botany, Vol. 58(4), 815-825. http://dx.doi.org/10.1093/jxb/erl153

Heilman, J.L., Kanemasu, E.T., Rosenberg, N.J., and Blad, B. L. (1976). Thermal scanner measurement of canopy temperatures to estimate evapotranspiration. Remote Sensing of Environment, 5, 137-145. http://dx.doi.org/10.1016/0034-4257(76)90044-4

Huang, Y., Fipps, G., Maas, S.J., and Fletcher, R.S. (2009). Airborne remote sensing for detection of irrigation canal leakage. Irrigation and Drainage, 59, 524-534. http://dx.doi.org/10.1002/ird.511

Idso, S.B. (1982). Non-water-stressed baselines: A key to measuring and interpreting plant water stress. Agricultural Meteorology, 27, 59-70. http://dx.doi.org/10.1016/0002-1571(82)90020-6

Inoue, Y. (1990). Remote detection of physiological depression in crop plants with infrared thermal imagery. Japanese Journal of Crop Science, 59(4), 762-768. http://dx.doi.org/10.1626/jcs.59.762

Irmak, S., Haman, D.Z., \& Bastug, R. (2000). Determination of crop water stress index for irrigation timing and yield estimation of corn. Agronomy Journal, 92(6), 1221-1227. http://dx.doi.org/10.2134/agronj2000.9261221x

Jackson, R.D., Idso, S.B., Reginato, R.J., and Pinter, P.J. (1981). Canopy temperature as a crop water stress indicator. Water Resources Research, 17, 1133-1138. http://dx.doi.org/10.1029/WR017i004p01133

Jensen, J. R., (1996). Introductory digital image processing--A remote sensing perspective. Saddle River, New Jersey USA: Prentice Hall, Inc., pp. 197-256.

Jiménez-Bello, M.A., Ballester, C., Castel, J.R., \& Intrigliolo, D.S. (2011). Development and validation of an automatic thermal imaging process for assessing plant water status. Agricultural Water Management, 98, 1497-1504. http://dx.doi.org/10.1016/j.agwat.2011.05.002

Kar, G. \& Kumar, A. (2007). Surface energy and crop water stress index in groundnut under irrigated ecosystem. Agricultural and Forest Meteorology, 146, 94-106. http://dx.doi.org/10.1016/j.agrformet.2007.05.008

Kashefipour, S.M., Broomand, S. \& Ghannad, S.T. (2006). The effect of water stress on yield and canopy-air temperature difference for spring corn. Journal of Agronomy, 5(3), 401-405. http://dx.doi.org/10.3923/ja.2006.401.405

Leinonen, I. \& Jones, H.G. (2004). Combining thermal and visible imagery for estimating canopy temperature and identifying plant stress. Journal of Experimental Botany, 55 (401), 1423-1431. http://dx.doi.org/10.1093/jxb/erh146

Mahan, J. R., Burke, J.J., Wanjura, D.F., \& Upchurch, D.R. (2005). Determination of temperature and time thresholds for BIOTIC irrigation of peanut on the Southern High Plains of Texas. Irrigation Science, 23(4), 145-152. http://dx.doi.org/10.1007/s00271-005-0102-9

McCann, I.R. \& Stark, J.C. (1993). Method and apparatus for variable application of irrigation water and chemicals. U.S. Patent No. 5,246,164.

Meron, M., Tsipris, J., \& Charitt, D. (2003). Remote mapping of crop water status to assess spatial variability of crop stress. In: J. Stafford and A. Werner (Eds.), Precision agriculture, Proceedings of the 4th European Conference on Precision Agriculture, Berlin, Germany, (pp. 405-410), Wagningen Academic Publishers.

Moran, M.S., Clarke, T.R., Inoue, Y. \& Vidal, A. (1994). Estimating crop water deficit using the relation between surface-air temperature and spectral vegetation index. Remote Sensing of Environment, 46(3), $246-263$. http://dx.doi.org/10.1016/0034-4257(94)90020-5

Moran, M.S., Williams, D.G., Goodrich, D., Chehbouni, A., Begue, A., Boulet, G., Davis, R., Dedieu, G., Eichinger, W., Everitt, J., Goff, B., Harlow, C., Hymer, D., Kahle, A., Keefer, T., Kerr, Y.H., Marsett, R., Nouvellon, Y., Qi, J., Schaeffer, S., Schieldge, J., Snyder, K., Toth, J., Watts, C., \& Yucel, I. (1998). Remote sensing of semi-arid ecosystem function in the Upper San Pedro River basin, Arizona. Special Symposium on Hydrology, American Meteorological Society, Phoenix, AZ. [Online] Available: http://www.tucson.ars.ag.gov/salsa/archive/publications/ams_preprints/moran.PDF (October 20, 2011) 
Pennington, D. A., \& Heatherly, L. (1989). Effects of changing solar radiation on canopy-air temperatures of cotton and soybeans. Agricultural and Forest Meteorology, 46, 1-14. http://dx.doi.org/10.1016/0168-1923(89)90108-1

Peters, R.T. \& Evett, S.R. (2008). Automation of a center pivot using the temperature-time-threshold method of irrigation scheduling. Journal of Irrigation and Drainage Engineering, 134(3), $286-291$. http://dx.doi.org/10.1061/(ASCE)0733-9437(2008)134:3(286)

Pinter, P.J., \& Reginato, R.J. (1981). Thermal infrared techniques for assessing plant water status. In: Irrigation Scheduling for Water and Energy Conservation in the 80's - Proceedings of the ASABE Irrigation Scheduling Conference. St. Joseph, MI.: ASABE.

Qi, J., Moran, M.S., Goodrich, D.C., Marsett, R., Scott, R., Chehbouni, A., Schaeffer, S., Schieldge, J., Williams, D., Keefer, T., Cooper, D., Hipps, L., Eichinger, W. \& Ni, W. (1998). Estimation of evapotranspiration over the San Pedro riparian area with remote and in-situ measurements. Special Symposium on Hydrology, American Meteorological Society, Phoenix, [Online]. AZ. Available: http://www.tucson.ars.ag.gov/salsa/archive/publications/ams_preprints/qi.PDF (October 20, 2011).

Shimoda, S., \& Oikawa, T. (2008). Characteristics of canopy evaporation from a small heterogeneous grassland using thermal imaging. Environmental and Experimental Botany, 63, $102-112$. http://dx.doi.org/10.1016/j.envexpbot.2007.12.006

Smith, R.C.G., Prathapar, S.A., Barrs, H.D., \& Slavich, P. (1989). Use of a thermal scanner image of a water stressed crop to study soil spatial variability. Remote Sensing of Environment, 29, 111-120. http://dx.doi.org/10.1016/0034-4257(89)90020-5

Stockle, C.O. \& Dugas, W.A. (1992). Evaluating canopy temperature-based indices for irrigation scheduling. Irrigation Science, 13, 31-37. http://dx.doi.org/10.1007/BF00190242

Thomson, S.J., Harris, F.A., Sullivan, D.G., Rowland, D.L. \& Maw, B.W. (2005). Challenges and solutions for low altitude monitoring of crop status using thermal and reflective techniques. In: Proceedings of the First Asian Conference on Precision Agriculture, Aug 4-7, 2005, Toyohashi, Japan, CDROM, 170-180.

Thomson, S. J. \& D. G. Sullivan. (2006). Crop status monitoring using multispectral and thermal imaging systems for accessible aerial platforms. American Society of Agricultural Engineers (ASABE) Technical Paper No. 061179. St. Joseph, MI. USA: ASABE.

Wanjura, D.F., Upchurch, D.R., Sassenrath-Cole, G.F. \& DeTar, W.R. (1995). Calculating time thresholds for irrigation scheduling. In: Proceedings of the 1995 Beltwide Cotton Conferences, Jan. 4-7, 1995, San Antonio, TX, 449-452.

Wilson, D.L. (2011). GPS WAAS accuracy. David L. Wilson's GPS Accuracy Web Page. [Online] Available: http://users.erols.com/dlwilson/gpswaas.htm (October 20, 2011).

Zhang, R., Hongbo, S., Li, Z., Sun, X., Tang, X., \& Becker, F. (2001). The potential information in the temperature difference between shadow and sunlit surfaces and a new way of retrieving soil moisture. Science in China (Series D - Earth Science), 44(2), 112-123. http://dx.doi.org/10.1007/BF02879654

Table 1. Weather variables corresponding with thermal imaging over-flights (illustrated in Fig. 6).

\begin{tabular}{|c|c|c|c|c|c|c|}
\hline Date & DOY & Time & PAR & Air Temp & Rel. Humidity & Wind Speed \\
\hline & & & (umol/sq-m s) & (deg. C) & \% & (m/sec) \\
\hline $7 / 26 / 2005$ & 207 & $14: 18$ & 1245 & 36.22 & 45.5 & 0.447 \\
\hline $8 / 2 / 2005$ & 214 & $14: 50$ & 617 & 34.94 & 53.9 & 0.939 \\
\hline $8 / 9 / 2005$ & 221 & $13: 51$ & 1319 & 34.28 & 47.5 & 1.296 \\
\hline $8 / 17 / 2005$ & 229 & $13: 40$ & 1332 & 30.83 & 59.7 & 1.520 \\
\hline
\end{tabular}



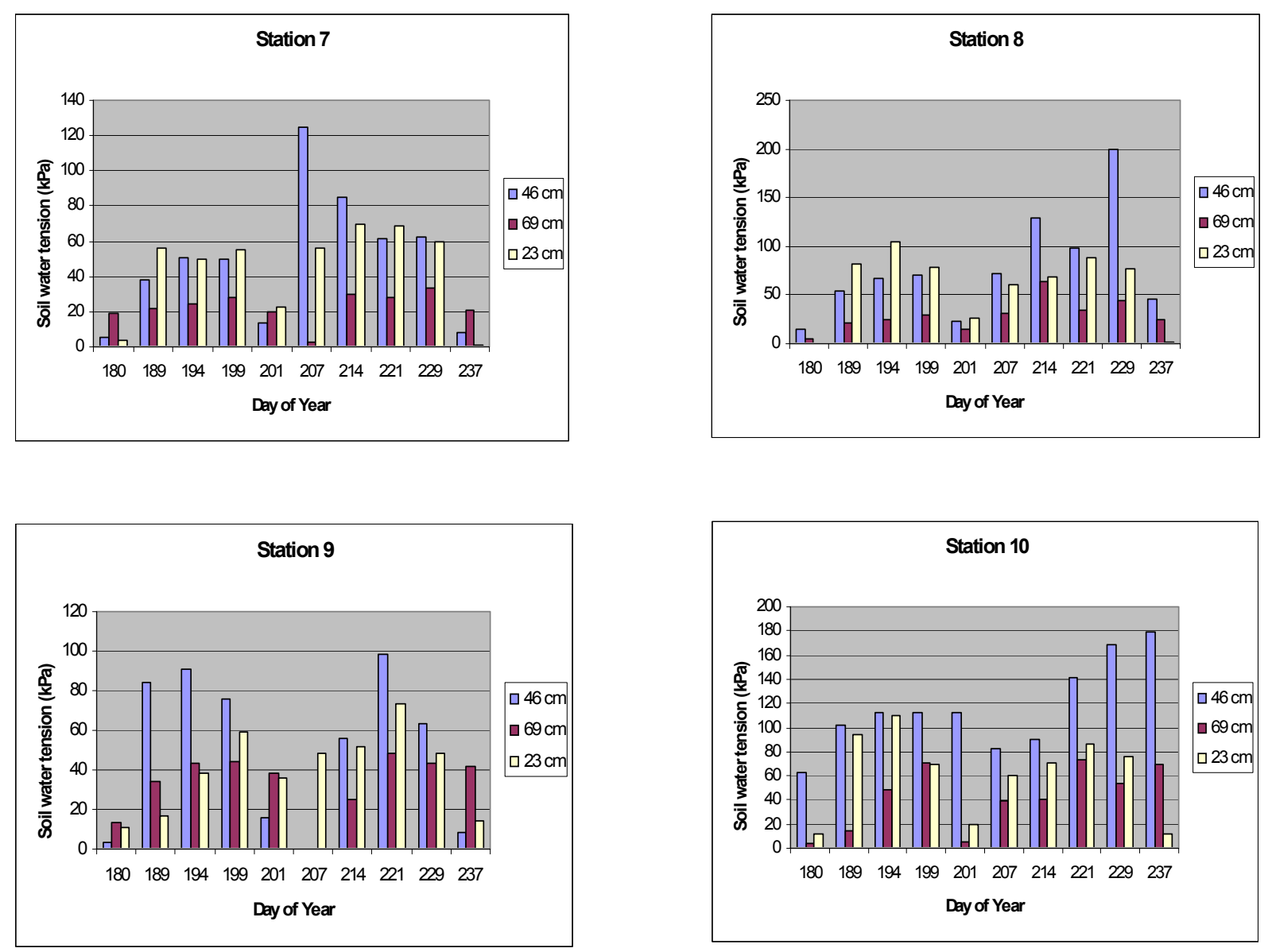

Figure 1. SWS readings at four field stations (with spatial locations shown in Fig. 6). Higher readings indicate drier soil conditions

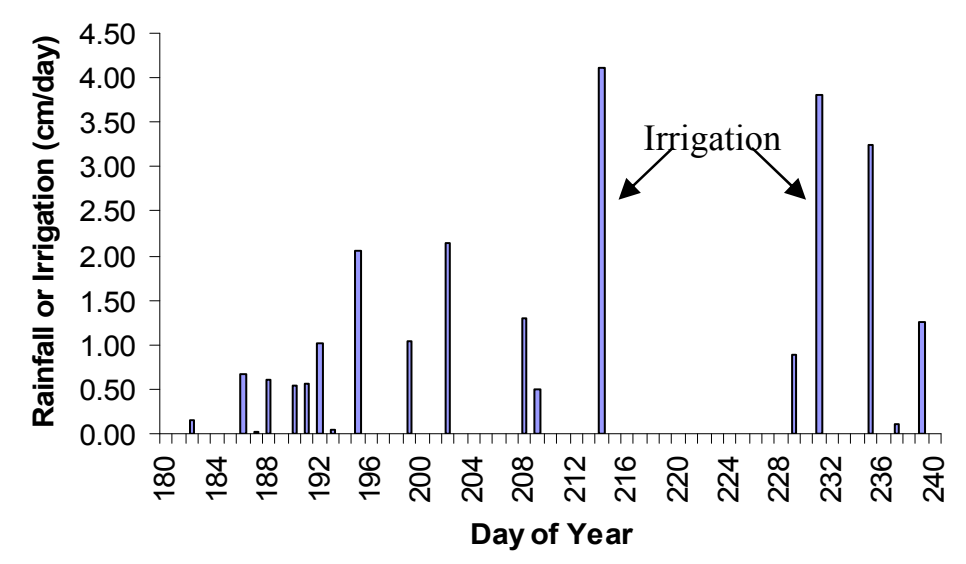

Figure 2. Rainfall and irrigation events 


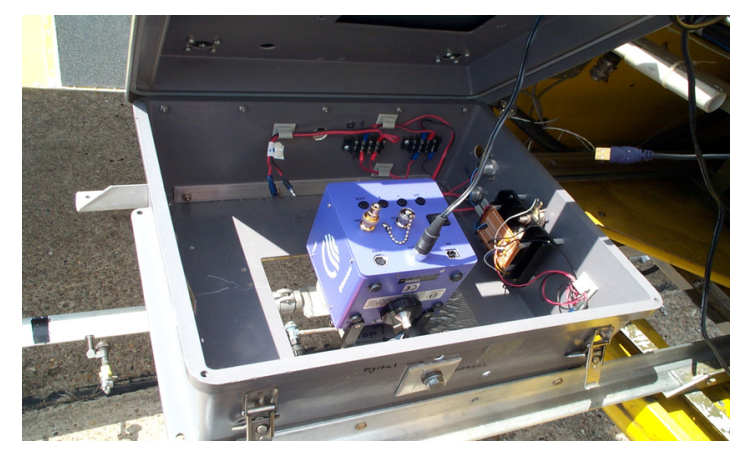

Figure 3. Electrophysics PV-320T thermal imaging camera mounted in agricultural aircraft
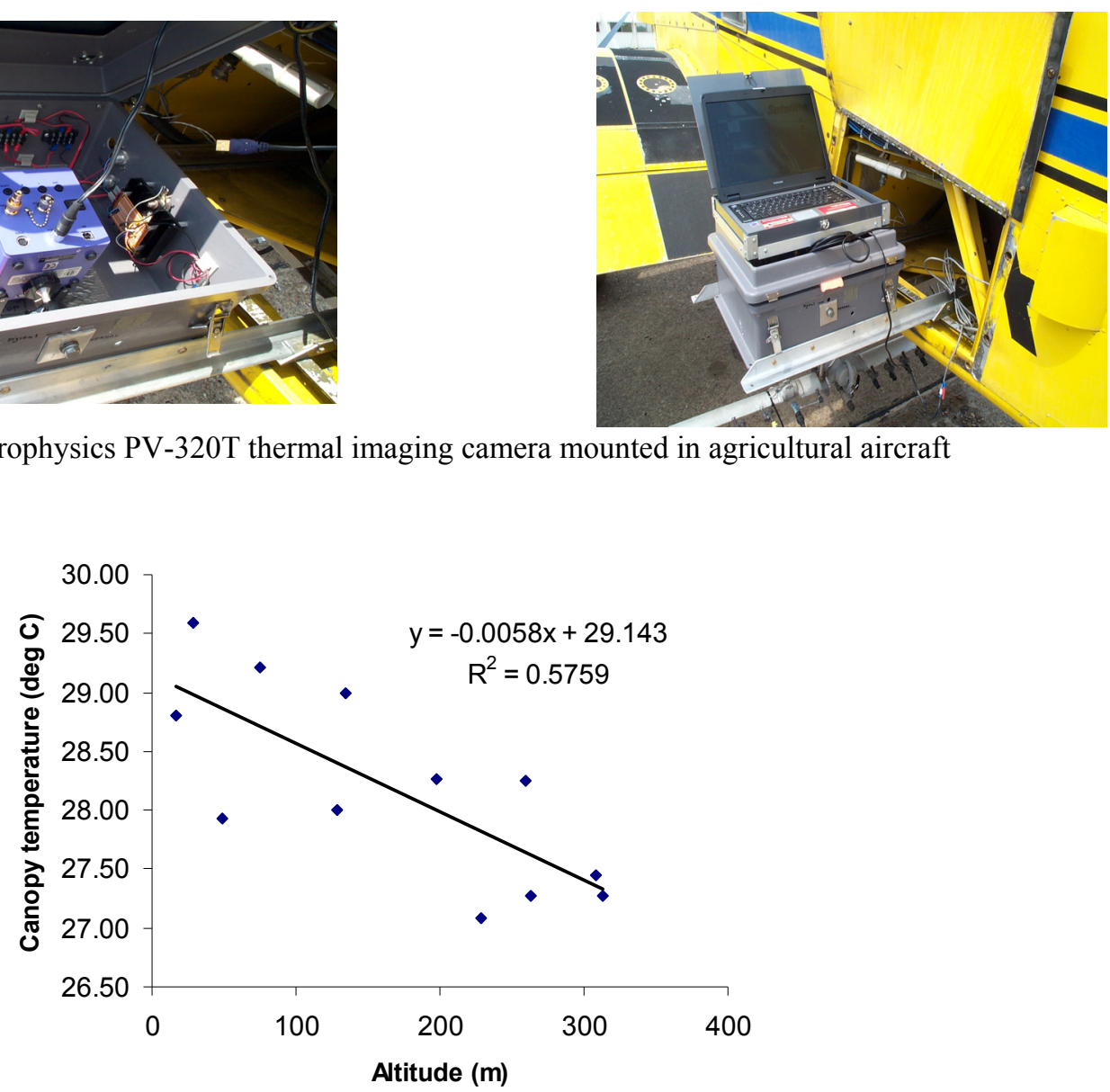

Figure 4. Canopy temperature as a function of altitude

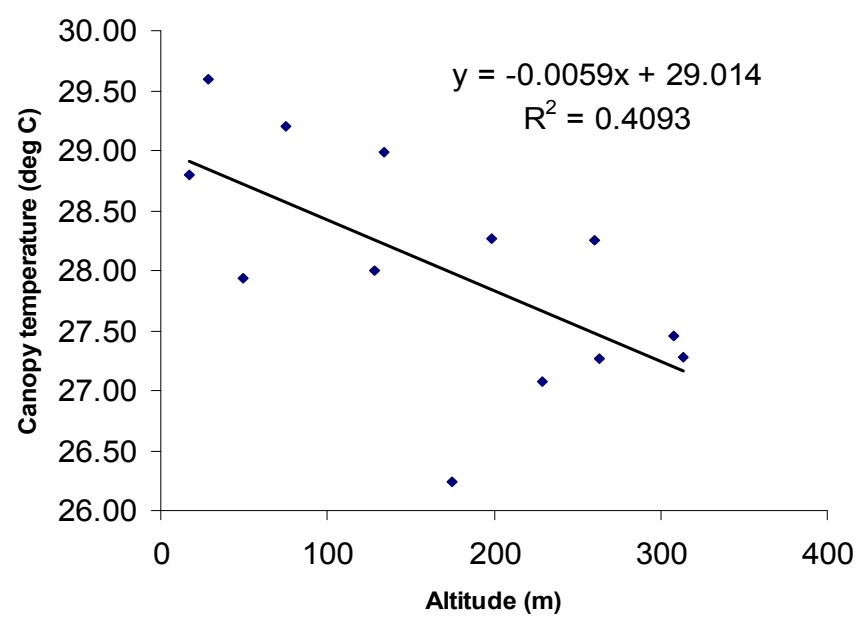

Figure 5. Canopy temperature as a function of altitude including single temperature value obtained from the image while cloud blocked a portion of incoming solar radiation 


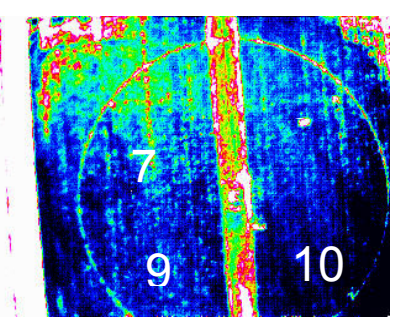

07-26-05 (DOY 207)

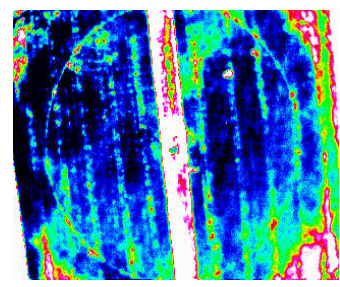

08-09-05 (DOY 221)

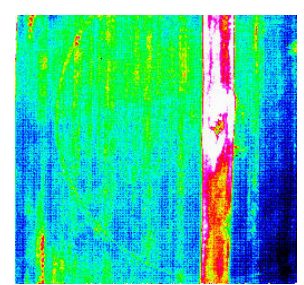

08-02-05 (DOY 214)

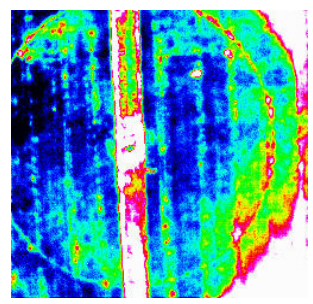

08-17-05 (DOY 229)

Figure 6. Thermal imagery illustrating temporal canopy temperature responses. A drying cycle without measurable precipitation occurred during the period between DOY 221 to DOY 229. SWS stations are indicated on the 07-26-05 image

A

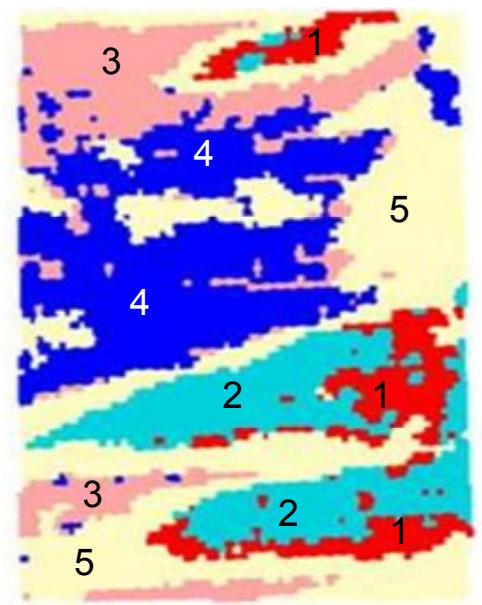

Legend:

$1=$ high $\Delta$ canopy cover, high canopy temperature

$2=$ low $\Delta$ canopy cover, high canopy temperature

$3=$ high $\Delta$ canopy cover, low canopy temperature

$4=$ low $\Delta$ canopy cover, low canopy temperature

$5=$ not significantly autocorrelated

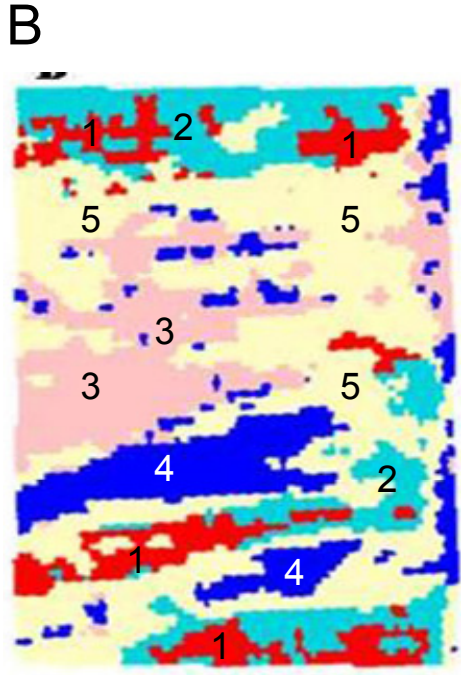

Legend:

$1=$ high yield, high $\Delta$ canopy cover 2 = low yield, high $\Delta$ canopy cover $3=$ high yield, low $\Delta$ canopy cover $4=$ low yield, low $\Delta$ canopy cover $5=$ not significantly autocorrelated

Figure 7. Geospatial relationships between yield, change in canopy cover determined my multispectral imaging, and canopy temperature as determined by thermal imaging. Numbers correspond to relative shading in the image 


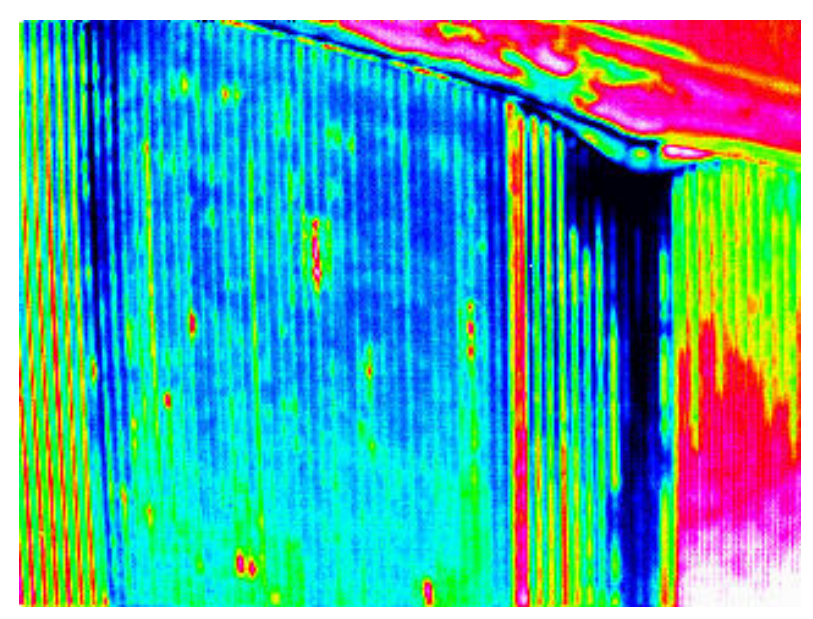

Figure 8 . Thermal image of a furrow irrigated field showing system leaks and misapplication three days prior (right side of the image) 